\title{
Low rate of germline AIP mutations in patients with apparently sporadic pituitary adenomas before the age of 40: a single-centre adult cohort
}

\author{
Veronica Preda ${ }^{1,3}$, Márta Korbonits ${ }^{2}$, Simon Cudlip ${ }^{4}$, Niki Karavitaki ${ }^{1}$ and \\ Ashley B Grossman ${ }^{1}$
}

${ }^{1}$ Oxford Centre for Diabetes Endocrinology and Metabolism, Oxford OX3 7LE, UK, ${ }^{2}$ Department of Endocrinology, Barts and the London School of Medicine, Queen Mary University of London, London, UK, ${ }^{3}$ Kolling Institute, Royal North Shore Hospital, University of Sydney, St Leonards, New South Wales 2065, Australia and ${ }^{4}$ Department of Neurosurgery, John Radcliffe Hospital, Oxford, UK
Correspondence should be addressed to V Preda

Email

veronicapreda01@gmail.com

\begin{abstract}
Aim: To study the prevalence of germline mutations of the aryl-hydrocarbon receptor interacting protein (AIP) gene in a large cohort of patients seen in the Oxford Centre for Diabetes Endocrinology and Metabolism (OCDEM), UK, with apparently sporadic pituitary adenomas, who were either diagnosed or had relevant clinical manifestations by the age of 40 years.
\end{abstract}

Patients: We prospectively investigated all patients who were seen at Oxford University Hospital, OCDEM, and a tertiary referral centre, between 2012 and 2013, and presented with pituitary tumours under the age of 40 years and with no family history: a total of 127 patients were enrolled in the study.

Methods: Leukocyte-origin genomic DNA underwent sequence analysis of exons 1-6 and the flanking intronic regions of the AIP gene (NM_003977.2), with dosage analysis by multiplex ligation-dependent probe amplification.

Results: AIP variants were detected in $3 \%$ of the 127 patients, comprising four of 48 patients with acromegaly (8\%), 0 of 43 with prolactinomas, 0 of the 20 patients with non-functioning adenomas, 0 of 15 with corticotroph adenomas and 0 of one with a thyrotroph adenomas. Definite pathogenetic mutations were seen in $2 / 4$ variants, comprising $4.2 \%$ of patients with acromegaly.

Conclusions: This prospective cohort study suggests a relatively low prevalence of AIP gene mutations in young patients with apparently sporadic pituitary adenomas presenting to a tertiary pituitary UK centre. Those with somatotroph macroadenomas have a higher rate of AIP mutation. These findings should inform discussion of genetic testing guidelines.

\section{Introduction}

Pituitary adenomas are common in the general population and, with the increasing use of imaging of the head and neck, are being more frequently detected, with a prevalence of some 80 cases/100 $000(1,2)$.

To date, a number of genetic conditions have been associated with pituitary tumours, including established common associations (MEN1, Carney complex, McCune-Albright syndrome) and rarer, emerging associations (MEN4, infant-onset adrenocorticotrophin
(ACTH)-secreting pituitary blastoma due to a DICER1 mutation and familial paraganglioma-associated succinate dehydrogenase (SDH) mutations (SDHB, SDHC, $S D H D))(3,4,5,6,7,8)$. Of the common genetic associations, it is important to consider mutations in MEN1 in all young patients with sporadic isolated pituitary macroadenomas, particularly prolactinomas (9). While the majority of adult pituitary adenomas occur sporadically without evidence of inheritance, it is now being (c) 2014 European Society of Endocrinology Printed in Great Britain
Published by Bioscientifica Ltd. 
increasingly recognised that in a number of such patients the pituitary tumour may be part of a familial syndrome, familial isolated pituitary adenomas (FIPA), even in the absence of a known family history. FIPA is a clinical diagnosis based on the presence of a pituitary adenoma in more than one family member without other associated features of a well-characterised inherited syndrome (2). Although the majority of families have yet to have the causative gene identified, some $20 \%$ of cases show a germline mutation in the aryl-hydrocarbon receptor interacting protein $(A I P)$ gene: this is particularly evident in families with acromegaly and prolactinomas $(10,11,12,13)$.

$A I P$ is a 330 amino acid protein which appears to function as a tumour suppressor gene $(14,15)$. The currently recognised genetic alterations include nonsense, missense, deletion/insertion and splice-site mutations, and large deletions and promoter mutations $(3,11,16)$. The vast majority of AIP mutations result in a truncated or missing protein. Over 70 different mutations have been described in the literature, including those at certain specific hotspots $(2,12,17)$. In patients with such germline mutations, analysis of tumour DNA has shown a loss of heterozygosity of the AIP gene located at 11q13.3 in most of the cases (11).

While familial pituitary tumours are uncommon, it is increasingly recognised that patients with apparently sporadic tumours, especially younger ones, may still harbour germline mutations of AIP as the disease has relatively low penetrance. Tichomirowa et al. (18) studied 163 sporadic pituitary macroadenoma patients diagnosed at an age younger than 30 years, and found that $11.7 \%$ of them had germline mutations of AIP. Cazabat et al. (19) described a large cohort of 443 patients, half of which were below 40 years of age: the prevalence of sporadic AIP mutation was $7.2 \%$ (16 of 222) in this group. Similarly, Cai et al. (20) reported a prevalence of AIP mutations of $3.9 \%$ for pituitary adenomas and $9.3 \%$ for somatotroph tumours in the Han Chinese population. We have now explored the frequency of AIP mutation, as well as the mutation types, in patients with sporadic pituitary adenomas with definitive symptoms or a clinical diagnosis by the age of 40 years, in our tertiary referral centre in the UK.

\section{Patients and methods}

\section{Patients}

In order to estimate the prevalence of AIP mutations in the different subtypes of sporadic pituitary adenomas, we prospectively enrolled 127 consecutive adult patients with clinical disease onset before the age of 40 years in a prospective cohort study at the Oxford Centre for Diabetes Endocrinology and Metabolism, over 12 months, between January 2012 and 2013. Our age criteria were chosen to allow for consideration of the time lag from symptoms to clinical diagnosis, and thus that patients presenting at the age of 40 years may actually have had a clinical syndrome dating back many years earlier. These patients were a mix of old and new patients to our centre; however, all already had a diagnosis of pituitary adenoma. It was the first time they had been offered genetic testing. Originally, there were 135 patients identified but eight declined testing. This study was approved by the local Ethics Committee, and the Cambridgeshire Ethics Committee, as part of a larger study by $\mathrm{M}$ Korbonits into the genetics of pituitary tumours, their presentations and associations: all patients gave written informed consent.

A detailed clinical and family history was taken in all cases. None of the patients had a known personal or familial history of MEN types 1 or 4, Carney complex, McCune-Albright syndrome or known FIPA. Data were collected regarding age at diagnosis and at onset of symptoms/signs, gender, hormonal profile at diagnosis, imaging (including CT or magnetic resonance imaging (MRI)), and pathological diagnosis (for those with tumour resection) for all patients. The adenomas were classified into microadenomas (being $<10 \mathrm{~mm}$ diameter in size) and macroadenomas (being $>10 \mathrm{~mm}$ diameter in size). Of the cases that were tested as AIP positive, with a pathological mutation, genetic counselling was provided, and first-degree relatives who consented to the process (offspring, siblings, and parents) were recruited and tested. Those relatives with mutations were then tested for their pituitary profile and underwent MRI in order to ascertain any underlying pathology.

\section{Methods}

Genetic testing - We performed sequence analysis of exons 1-6 and the flanking intronic regions of the AIP gene (NM_003977.2). Dosage analysis by multiplex ligation-dependent probe amplification (MLPA) was determined using the MRC-Holland kit P244-B1.

Genomic DNA was extracted from the peripheral leucocytes by using standard procedures. The six coding exons of AIP were PCR-amplified using specific primers for each amplicon tagged with $5^{\prime}$ M13 tails to allow sequencing to be performed with universal M13 primer. Real-time PCR was carried out with the Taq-Man system using ready-made AIP probe-primer kits. The reactions 
were carried out as previously described in author M Korbonits's laboratory (11). Unidirectional sequencing was carried out using Big Dye terminator chemistry on an ABI 3730 sequencer (Applied Biosystems). The sequences were compared with the published template (accession no. NM_003977.2) using Mutation Surveyor (version 3.95; SoftGenetics, State College, PA, USA): this involves sequencing of the exons and exon-intron junctions (detects 90\% mutations). If no mutation was detected by sequencing, MLPA dosage analysis was carried out to look for partial or whole-gene deletions. MLPA analysis was carried out according to the manufacturer's instructions using the P244-B1 MLPA kit available from MRC-Holland, Amsterdam, The Netherlands. The pathogenicity of novel missense mutations was investigated using Alamut Mutation Interpretation software (version 2.1, Interactive Biosoftware, Rouen, France).

The AIP sequence variants were compared with human single-nucleotide polymorphism (SNP) databases (dsSNP http://www.ncbi.nlm.nih.gov/SNP/snp_summary. cgi), and AIP mutation data from genetically diverse populations (21).

\section{Statistical analyses}

Clinical, biochemical and radiological data were recorded anonymously in a Microsoft Excel 2011 computer database. For descriptive statistics, all values are given as means \pm s.D.

\section{Results}

\section{Patient cohort characteristics}

A total of 127 patients presenting with apparently sporadic pituitary adenomas with relevant manifestations before the age of 40 years were enrolled, including 67 females (53\%) and 60 males (47\%). Of these, 48 (38\%) had acromegaly or gigantism, with equal distribution observed for both male and female patients. There were 45 patients with acromegaly and three male patients with gigantism. Of the three patients with gigantism, one was AIP positive: 43 patients (34\%) had prolactinomas, of which 31 were macroadenomas and 12 microadenomas, and all microadenomas were seen in female subjects. In total there were 100 macroadenomas and 27 microprolactinomas. Of the macroprolactinomas, 15 were present in males and 16 in females. In addition, 20 patients (16\%) had non-functioning adenomas, 15 (11.5\%) had Cushing's disease (all microadenomas) and one patient (0.5\%) had a thyrotrophinoma (macroadenoma). The individual features of each sporadic pituitary adenoma type are given in Table 1.

\section{AIP sequencing}

AIP sequence variants were observed in $4 / 127$ patients (3\%), of which two (1.5\%) patients had sequence variations that would definitively result in altered AIP expression or function based on published data. MLPA did not reveal any large deletions, and no promoter mutation was found in our cohort. All four mutations/variants were found in the cohort of 48 patients with acromegalygigantism, all of whom had somatotroph adenomas on histology: there were two males and two females, and all four were macroadenomas. The onset of clinical symptoms was in the age range of 17-37 years; the actual range of ages at diagnosis was 21-41 years. In the AIP-negative cohort, there was a more varied clinical phenotype, a mixture of histological subtypes, older average age with a mean of 31 years of age at diagnosis and 28 years at clinical symptomatology, demonstrating a time lag from the initial onset of symptoms to diagnosis of an average of

Table 1 Features of sporadic tumour type.

\begin{tabular}{|c|c|c|c|c|c|c|}
\hline \multirow[b]{2}{*}{ Tumour type } & \multirow[b]{2}{*}{$\boldsymbol{n}(\%)$} & \multirow{2}{*}{$\begin{array}{l}\text { Age (years) at } \\
\text { diagnosis } \\
\text { (mean } \pm \text { s.D.) }\end{array}$} & \multirow{2}{*}{$\begin{array}{c}\text { Age (years) at } \\
\text { development of clinical } \\
\text { symptoms (mean } \pm \text { s.D.) }\end{array}$} & \multirow{2}{*}{$\begin{array}{l}\text { Maximum tumour } \\
\text { diameter }(\mathrm{mm}) \\
(\text { mean } \pm \text { s.D. })\end{array}$} & \multicolumn{2}{|c|}{ Gender } \\
\hline & & & & & $\mathrm{M}$ & $\mathrm{F}$ \\
\hline Somatotrophinomas & $48(38)$ & $34 \pm 8.1$ & $29.5 \pm 8.1$ & $20 \pm 12.2$ & 24 & 24 \\
\hline Prolactinomas & $43(34)$ & & & & & \\
\hline Macroadenomas & $31(72)^{a}$ & $28.8 \pm 8.6$ & $27.2 \pm 8.1$ & $19.9 \pm 8.1$ & 15 & 16 \\
\hline Microadenomas & $12(28)^{a}$ & $23.3 \pm 5.7$ & $22 \pm 5.1$ & $6.3 \pm 1$ & 0 & 12 \\
\hline Non-functioning adenomas & $20(16)$ & $35 \pm 7$ & $33 \pm 6$ & $22.1 \pm 5$ & 11 & 9 \\
\hline Cushing's disease & $15(11.5)$ & $30 \pm 8.7$ & $28 \pm 7.8$ & $5.3 \pm 2.4$ & 5 & 10 \\
\hline Thyrotrophinoma & $1(0.5)$ & 33 & - & - & 0 & 1 \\
\hline
\end{tabular}


3 years, similar to the time lag of 2.75 years of clinical symptoms to diagnosis in the AIP-positive cohort.

In terms of histopathology, of the 48 somatotroph cases that were able to be subclassified, there were nine densely granulated tumours, 16 sparsely granulated tumours and two mixed sparsely densely granulated tumours. Sparsely granulated somatotrophinomas are thought to be more aggressive, with higher recurrence rates (22). In our patient cohort, both female patients with AIP pathological variants of uncertain pathogenicity had sparsely granulated tumours, while both male patients with pathological AIP variants had densely granulated somatotroph tumours. In addition, the MIB1 index (Monoclonal Mouse anti-human Ki-67 Antigen, Clone MIB-1) in the two pathological AIP mutation-positive patients and two non-pathological AIP-positive variants was raised $\geq 3 \%$, in comparison with other nonsomatotroph subtypes.

\section{Patient 1}

Gigantism was diagnosed at the age of 21 years in a male referred with excess growth continuing after puberty from the age of 17 years, to a final height of to $202.5 \mathrm{~cm}$. He had a macroadenoma, which histologically revealed a densely granulated somatotroph tumour. The AIP mutation was found to be heterozygous for a previously described splicesite mutation c.807C $>$ T. It is of note that this mutation does not cause change in an amino acid, but is thought to reduce the expression of the AIP protein $(3,11)$.

\section{Patient 2}

This male patient presented with acromegaly at the age of 41 years to a rheumatologist with bilateral carpal tunnel syndrome and joint pains, with a clinical history of symptoms dating back to the age of 35 years. He was found to have a known pathogenic heterozygous missense mutation, mutation c.911G > A p.R304Q. Clinically, our patient had marked clinical signs of acromegaly and a history of three pituitary operations, which were noncurative. His most recent surgical histopathology has demonstrated a densely granulated somatotroph adenoma staining for growth hormone $(\mathrm{GH})$ and scant luteinizing hormone, follicle-stimulating hormone.

\section{Patient 3}

This 26-year-old female presented to her family doctor with menstrual disturbance, obstructive sleep apnoea and excess sweating, and was diagnosed with acromegaly. Pathology demonstrated a sparsely granulated somatotroph adenoma with a raised MIB index of $>3 \%$. Genetic sequencing showed her to be heterozygous for intronic variant c. $100-18 \mathrm{C}>\mathrm{T}$.

\section{Patient 4}

Acromegaly was diagnosed in a 29-year-old female with a history of an acute visual field defect on a background of 2 years of amenorrhoea and carpal tunnel syndrome. The pathology demonstrated a sparsely granulated somatotroph macroadenoma with expression of GH staining in $40 \%$ of cells. She was found to be heterozygous for missense variant c. $47 \mathrm{G}>\mathrm{A}$, in exon 1 of $A I P$, a variant of uncertain pathogenic significance (23).

\section{Familial predictive testing}

Familial predictive testing was possible in the relatives of two patients (patients 1 and 2) with definitive literaturebased AIP mutations. The family pedigrees are shown for these two patients (Figs 1 and 2). On familial testing, patient 1's maternal grandmother, mother and sister were asymptomatic carriers with normal anterior pituitary profile and no MRI evidence of pituitary adenomas (i.e. non-penetrant despite autosomal dominance inheritance). Studies of these patient's families showed that asymptomatic relatives carried the same mutation, c.807C $>$ T in patient 1's family, and c.911G $>$ A in patient 2 's family. Among these mutation carriers, MRI and biochemical testing revealed an undiagnosed microprolactinoma in the younger sister of patient 2 , but no other adenomas in the remaining tested members of the families at this stage. For patient 2, genetic studies of his three children, two sons and one daughter, his youngest daughter aged 14 was noted to be a mutation carrier, with no clinically or biochemically apparent disease at this age. His two sisters, one older and one younger, also had genetic screening. They both were found to have c.911G $>$ A mutation, with the younger sister found to have a microprolactinoma and the older sister an asymptomatic carrier only at this stage. Our patient also reported about his seven-foot $(\mathrm{c} .200 \mathrm{~cm})$ tall maternal grandfather who was a boxer. It is, however, difficult to establish causality of the AIP mutation in the family, causing the microprolactinoma in his sister, as by far prolactinomas are the most frequent of pituitary tumours and its behaviour at this stage was not 'aggressive' in type, although clinical follow-up is pending. 


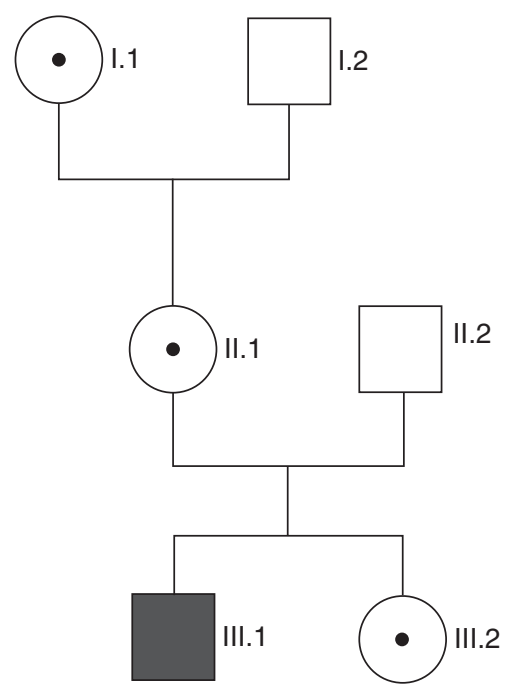

Affected male proband, with gigantism, c.807C > T mutation

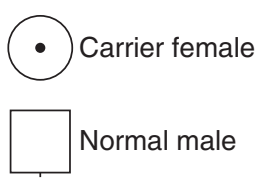

Figure 1

Family tree patient 1 .

\section{Discussion}

In the light of previous suggestions that germline mutations are not infrequently seen in patients with apparently sporadic pituitary adenomas, especially when presenting at a young age, we decided to prospectively evaluate consecutive adult patients with pituitary adenomas whose clinical features dated from $<40$ years of age in our single-centre adult cohort. A small group presented with microadenomas, usually with prolactinomas or Cushing's disease, but we were able to evaluate 100 patients with macroadenomas fulfilling these criteria. While non-functioning adenomas constitute the majority of tumours in patients presenting to our clinic out of the 100-120 new referrals per annum, most such patients fall into an older age group; in this series the majority of patients presented with macroadenomas and a clinical presentation of acromegaly-gigantism rather than non-functioning tumours (24).

In our patient group, no AIP variants were identified in any patient other than those with acromegaly; in two cases they were deemed to be definitely pathological, while in another two cases the issue regarding the pathogenicity of the variants is debated $(23,25)$. The missense variant c. $47 \mathrm{G}>\mathrm{A}$ in patient 4 has been described and reviewed recently in the literature in association with an aggressive non-functioning adenoma; our patient showed the clinical picture of a macroadenoma, with aggressive features of increased MIB1 and a sparse granulation pattern. Thus, the pathogenicity or otherwise of this variant remains unclear. Thus, this would constitute a prevalence of $2 \%$ definite and $4 \%$ possible of AIP mutations in patients with pituitary adenomas presenting with a history below the age of 40 years; in terms of acromegaly alone, the prevalence would be 4.2 and $8.4 \%$ respectively. We did not find mutations in patients with sporadic microprolactinomas or Cushing's disease, as noted by Cazabat et al. (19).

Over 70 different AIP mutations have been described in the literature, including 'hotspot' mutations $(12,17)$. The AIP mutation in patient 1 was found to be heterozygous for a previously described splice mutation c. $807 \mathrm{C}>\mathrm{T}$. It is of note that this mutation does not cause a change in amino acid, but is thought to reduce the expression of the AIP protein (11). Further carriers were
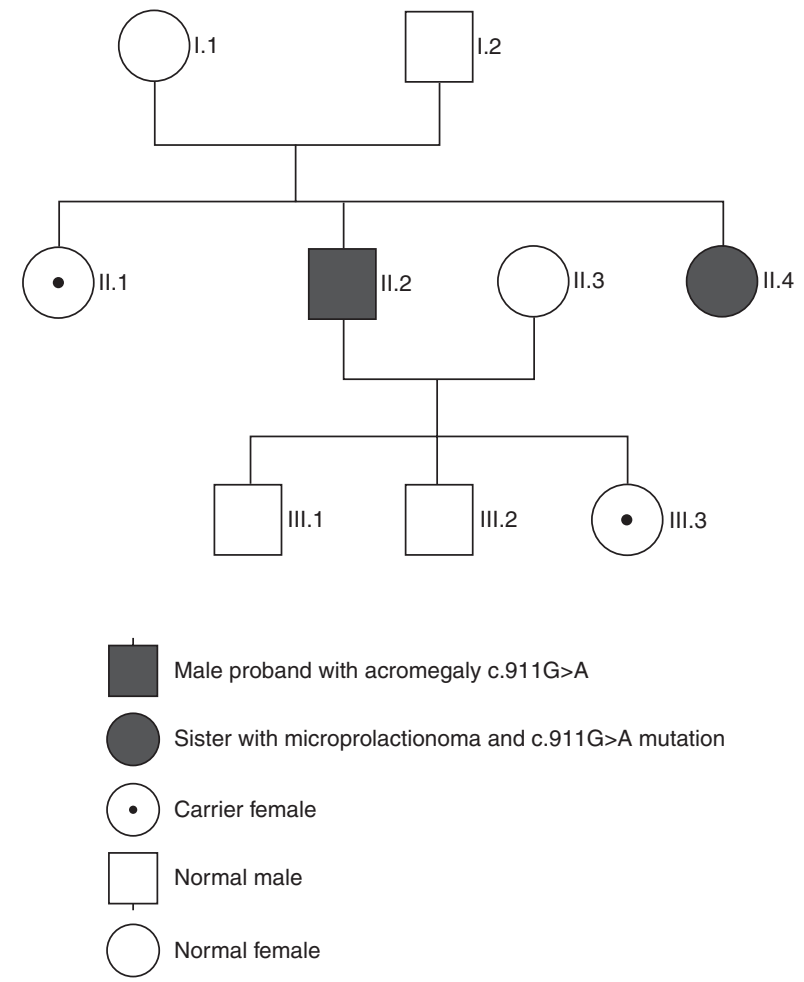

Figure 2

Family tree patient 2 . 
identified in his family and will be followed for clinical disease. In patient 2, the p.R304Q variant shows a relatively high background incidence in the general population of $\sim 0.1 \%$, but it is unequivocally associated with familial pituitary adenomas $(3,10,11)$. The AIP p.R304* is a common mutation, whereas the p.R304Q is less predominant; in our case it occurred in the setting of sporadic adenomas in a family of English-Irish heritage with known familiality (11). In our cohort, the screening of patient 2 for an AIP mutation, and its positive status, resulted in further familial screening. This led to the diagnosis of a younger sister with a prolactinoma, resulting in a clinical outcome for the screening and found AIP p.R304Q mutation carrier status in his older sister and daughter, both of whom will be followed for signs of clinical disease. In patient 3 , genetic sequencing showed her to be heterozygous for intronic variant c.100$18 \mathrm{C}>\mathrm{T}$. Although this variant has been compared with SNP database and the pathogenic potential of this variant is unclear, in this case it may be pathological, as previously described (26). Patient 4 was found to be heterozygous for a missense variant c. $47 \mathrm{G}>\mathrm{A}$, in exon 1 of $A I P$, a variant of uncertain pathogenic significance. This could be a SNP based on current functional classification data, as has been shown in a recent paper associated with an aggressive clinical course in a NFA (23).

In light of the significant number of patients and prospective recruitment of consecutive patients from a major academic centre devoted to pituitary disease, these results are likely to be very representative of sporadic pituitary adenomas of clinical significance in a tertiary referral centre in the UK, and probably in other nations. In previous series, slightly higher prevalence rates of AIP mutation were found. Cazabat et al. in a large prospective cohort from a single centre, noted an overall prevalence of $3.6 \%$ in their large series of 443 patients, with a prevalence of $7.2 \%$ in those presenting under 40 years of age. This is a little higher than our figure, but unlike their series we only saw AIP mutations in patients with acromegaly. Six of 148 patients with acromegaly in their series had either somatotroph tumours or mixed somatotroph/prolactin tumours, with a prevalence of $4 \%$ (19). We had relatively even gender ratios of mutations in our cohort, although with an admittedly smaller number of patients than that reported by Cazabat et al. (27). Tichimirowa etal. (18) studied 163 patients presenting at $<30$ years of age in a panEuropean collaboration, with $11.7 \%$ showing a pathological germline AIP mutation and a further $5.5 \%$ with possibly pathological mutations; the rates for acromegaly and prolactinomas were 13.3 and $11.5 \%$ respectively. Even taking into account the slightly lower age entry criterion compared with our study, these figures are still rather higher than that we report, although it should be noted that three of our four patients presented below 30 years of age. Our population of patients did not include paediatric referrals. The majority of AIP mutation-positive patients have an onset during their teenage years or in young adulthood (28).

The patients in our series only included adult patients presenting in outpatients, reducing the bias towards only large macroadenomas, which are far more likely to present acutely as an inpatient in the UK. The relative percentages of the different types of pituitary adenomas are different in a tertiary referral centre, as compared with those seen in an unselected general population, in which prolactinomas may be more frequently encountered. AIP mutations are more frequent in prolactinomas; hence the mutation rates quoted may be underestimated by such referral patterns. This applies to all studies reported from tertiary referral centres. Our study is a cross-sectional assessment of AIP mutation rates in our cohort, different to prior prevalence studies, which might explain the lack of AIP mutations found in other tumour types (including prolactinomas) than somatotrophs. In addition, we were restricted in our recruitment to the adult tertiary referral outpatient setting.

Once the mutations were identified in our patients, family members had predictive genetic testing of the family mutation. It is of interest that we have to date been unable to clearly identify family members with significantly large tumours. This may be a consequence of the limited penetrance of disease in AIP-positive mutation carriers, but only longer term studies with larger numbers will help to clarify this. Certainly, there is a strong case for continuing follow-up to these patients. The recommended surveillance by our group, based on the published literature and our own experience, suggests baseline clinical assessment with a pituitary profile and MRI imaging, then subsequent annual pituitary function testing (12) for all patients with pituitary adenomas (particularly prolactinomas and somatatrophinomas) regardless of AIP status. In the $A I P$-positive cohort with tumours, after definitive clinical management of the tumour, regular follow-up is recommended. This would preferably occur in large centres with a particular interest in pituitary disease in order to ensure continuation of the patient's eupituitary state, but also to review long-term outcome data.

\section{Conclusions}

This single-centre prospective cohort study follows on from the work of Tichomirowa et al. (18) and Cazabat et al. 
$(19,27)$. Extrapolating on the literature, we proposed limiting AIP testing to patients diagnosed or with symptoms before 40 years of age, applying these criteria to a prospective study of consecutive patients with pituitary adenomas referred to a single tertiary referral centre in the UK. Our results suggest that the rate of positive AIP mutations is lower than that previously reported, and in this series was only seen in patients with somatotroph tumours. Whether it is a worthwhile screening for AIP mutations with apparently sporadic pituitary adenomas will depend on the facilities in each country and centre, and cost considerations, but our experience suggests that we would agree that it should be limited to patients with a family history or presenting at $<40$ years of age with macroadenomas. The higher age cut off of 40 years allows for the time lag from symptomatology to presentation and clinical diagnosis, in which there is often a significant delay. Children with pituitary adenomas were not included in our study, but are a specific 'at risk' population of which all warrant testing.

\section{Declaration of interest}

The authors declare that there is no conflict of interest that could be perceived as prejudicing the impartiality of the research reported.

\section{Funding}

The laboratory work was funded by the Oxford Centre for Diabetes Endocrinology and Metabolism.

\section{Acknowledgements}

The authors thank the patients for taking part in our study, as well as Prof. Sian Ellard (Exeter, UK) for her contribution to our studies.

\section{References}

1 Fernandez A, Karavitaki N \& Wass JA. Prevalence of pituitary adenomas: a community-based, cross-sectional study in Banbury (Oxfordshire, UK). Clinical Endocrinology 201072 377-382. (doi:10.1111/j.1365-2265. 2009.03667.x)

2 Beckers A \& Daly AF. The clinical, pathological, and genetic features of familial isolated pituitary adenomas. European Journal of Endocrinology 2007157 371-382. (doi:10.1530/EJE-07-0348)

3 Leontiou CA, Gueorguiev M, van der Spuy J, Quinton R, Lolli F, Hassan S, Chahal HS, Igreja SC, Jordan S \& Rowe J. The role of the aryl hydrocarbon receptor-interacting protein gene in familial and sporadic pituitary adenomas. Journal of Clinical Endocrinology and Metabolism 200893 2390-2401. (doi:10.1210/jc.2007-2611)

4 Xekouki P, Azevedo M \& Stratakis CA. Anterior pituitary adenomas: inherited syndromes, novel genes and molecular pathways. Expert Review of Endocrinology and Metabolism 20105 697-709. (doi:10.1586/ eem.10.47)
5 Wildi-Runge S, Bahubeshi A, Carret A-S, Crevier L, Robitaille Y, Kovacs K, Horvath E, Scheithauer BW, Foulkes WD \& Deal C. New phenotype in the familial DICER 1 tumor syndrome: pituitary blastoma presenting at age 9 months. Endocrine Reviews 201132 P1-P777 (Abstract). (doi:10.1210/er.2011-0002)

6 Brahma A, Heyburn P \& Swords F. Familial prolactinoma occuring in association with SDHB mutation positive paraganglioma. Endocrine Abstracts 200919239.

7 Denes J, Swords FM, Xekouki P, Kumar AV, Maher ER, Ferscht N, Grieve J, Baldeweg S, Stratakis CA \& Korbonits M. Familial pituitary adenoma and paraganglioma syndrome - a novel type of multiple endocrine neoplasia. Endocrine Reviews 201233 OR41-OR42.

8 Beckers A. Means, motive, and opportunity: SDH mutations are suspects in pituitary tumors. Journal of Clinical Endocrinology and Metabolism 201398 2274-2276. (doi:10.1210/jc.2013-2125)

9 Cuny T, Pertuit M, Sahnoun-Fathallah M, Daly A, Occhi G, Odou MF, Tabarin A, Nunes ML, Delemer B, Rohmer V et al. Genetic analysis in young patients with sporadic pituitary macroadenomas: besides AIP don't forget MEN1 genetic analysis. European Journal of Endocrinology 2013168 533-541. (doi:10.1530/EJE-12-0763)

10 Daly AF, Vanbellinghen JF, Khoo SK, Jaffrain-Rea ML, Naves LA, Guitelman MA, Murat A, Emy P, Gimenez-Roqueplo AP, Tamburrano G et al. Aryl hydrocarbon receptor-interacting protein gene mutations in familial isolated pituitary adenomas: analysis in 73 families. Journal of Clinical Endocrinology and Metabolism 200792 1891-1896. (doi:10.1210/ jc.2006-2513)

11 Igreja S, Chahal HS, King P, Bolger GB, Srirangalingam U, Guasti L, Chapple JP, Trivellin G, Gueorguiev M, Guegan K et al. Characterization of aryl hydrocarbon receptor interacting protein (AIP) mutations in familial isolated pituitary adenoma families. Human Mutation 201031 950-960. (doi:10.1002/humu.21292)

12 Korbonits M, Storr H \& Kumar AV. Familial pituitary adenomas - who should be tested for AIP mutations? Clinical Endocrinology 201277 351-356. (doi:10.1111/j.1365-2265.2012.04445.x)

13 Chahal HS, Chapple JP, Frohman LA, Grossman AB \& Korbonits M. Clinical, genetic and molecular characterization of patients with familial isolated pituitary adenomas (FIPA). Trends in Endocrinology and Metabolism 201021 419-427. (doi:10.1016/j.tem.2010.02.007)

14 Grossman AB. The molecular biology of pituitary tumors: a personal perspective. Pituitary 200912 265-270. (doi:10.1007/s11102-0080158-7)

15 Vierimaa O, Georgitsi M, Lehtonen R, Vahteristo P, Kokko A, Raitila A, Tuppurainen K, Ebeling TM, Salmela PI, Paschke R et al. Pituitary adenoma predisposition caused by germline mutations in the AIP gene. Science 2006312 1228-1230. (doi:10.1126/science.1126100)

16 Georgitsi M, Heliövaara E, Paschke R, Kumar AV, Tischkowitz M, Vierimaa O, Salmela P, Sane T, De Menis E, Cannavò S et al. Large genomic deletions in AIP in pituitary adenoma predisposition. Journal of Clinical Endocrinology and Metabolism 200893 4146-4151. (doi:10.1210/jc.2008-1003)

17 Beckers A, Aaltonen LA, Daly AF \& Karhu A. Familial isolated pituitary adenomas (FIPA) and the pituitary adenoma predisposition due to mutations in the aryl hydrocarbon receptor interacting protein (AIP) gene. Endocrine Reviews 201334 239-277. (doi:10.1210/er.2012-1013)

18 Tichomirowa MA, Barlier A, Daly AF, Jaffrain-Rea ML, Ronchi C, Yaneva M, Urban JD, Petrossians P, Elenkova A, Tabarin A et al. High prevalence of AIP gene mutations following focused screening in young patients with sporadic pituitary macroadenomas. European Journal of Endocrinology 2011165 509-515. (doi:10.1530/EJE-11-0304)

19 Cazabat L, Bouligand J, Salenave S, Bernier M, Gaillard S, Parker F, Young J, Guiochon-Mantel A \& Chanson P. Germline AIP mutations in apparently sporadic pituitary adenomas: prevalence in a prospective single-center cohort of 443 patients. Journal of Clinical Endocrinology and Metabolism 201297 E663-E670. (doi:10.1210/jc.2011-2291)

20 Cai F, Zhang YD, Zhao X, Yang YK, Ma SH, Dai CX, Liu XH, Yao Y, Feng M, Wei JJ et al. Screening for AIP gene mutations in a Han Chinese 
pituitary adenoma cohort followed by LOH analysis. European Journal of Endocrinology 2013169 867-884. (doi:10.1530/EJE-13-0442)

21 Rowlands JC, Urban JD, Wikoff DS \& Budinsky RA. An evaluation of single nucleotide polymorphisms in the human aryl hydrocarbon receptor-interacting protein (AIP) gene. Drug Metabolism and Pharmacokinetics 201126 431-439. (doi:10.2133/dmpk.DMPK11-SC-013)

22 Larkin S, Reddy R, Karavitaki N, Cudlip S, Wass J \& Ansorge O. Granulation pattern, but not GSP or GHR mutation, is associated with clinical characteristics in somatostatin-naive patients with somatotroph adenomas. European Journal of Endocrinology 2013168 491-499. (doi:10.1530/EJE-12-0864)

23 Baciu I, Radian S, Capatina C, Botusan I, Aflorei ED, Stancu C, Dumitrascu A, Ciubotaru V \& Coculescu M. The P.R16H (C.47G >A) Aip gene variant in a case with invasive non-functioning pituitary macroadenoma and screening of a control cohort. Acta Endocrinologica 20139 97-108. (doi:10.4183/aeb.2013.97)

24 Pereira EA, Plaha P, Chari A, Paranathala M, Haslam N, Rogers A, Korevaar T, Tran D, Olarinde R, Karavitaki N et al. Transsphenoidal pituitary surgery in the elderly is safe and effective. British Journal of Neurosurgery 201328 616-621. (doi:10.3109/02688697.2013. 872225)
25 Zatelli MC, Torre ML, Rossi R, Ragonese M, Trimarchi F, degli Uberti E \& Cannavò $\mathrm{S}$. Should aip gene screening be recommended in family members of FIPA patients with R16H variant? Pituitary 201316 238-244. (doi:10.1007/s11102-012-0409-5)

26 Oriola J, Lucas T, Halperin I, Mora M, Perales MJ, Alvarez-Escolá C, Paz de MN, Díaz Soto G, Salinas I, Julián MT et al. Germline mutations of AIP gene in somatotropinomas resistant to somatostatin analogues. European Journal of Endocrinology 2013168 9-13. (doi:10.1530/EJE-120457)

27 Cazabat L, Libè R, Perlemoine K, René-Corail F, Burnichon N, GimenezRoqueplo AP, Dupasquier-Fediaevsky L, Bertagna X, Clauser E, Chanson $\mathrm{P}$ et al. Germline inactivating mutations of the aryl hydrocarbon receptor-interacting protein gene in a large cohort of sporadic acromegaly: mutations are found in a subset of young patients with macroadenomas. European Journal of Endocrinology 2007157 1-8. (doi:10.1530/EJE-07-0181)

28 Daly AF, Tichomirowa MA, Petrossians P, Heliövaara E, Jaffrain-Rea ML, Barlier A, Naves LA, Ebeling T, Karhu A, Raappana A et al. Clinical characteristics and therapeutic responses in patients with germ-line AIP mutations and pituitary adenomas: an international collaborative study. Journal of Clinical Endocrinology and Metabolism 201095 E373-E383. (doi:10.1210/jc.2009-2556)

Received 25 May 2014

Revised version received 14 August 2014

Accepted 2 September 2014 